\title{
Comparative Analysis of Online and Blended Online Learning
}

\author{
Azeem Unnisa ${ }^{1}$ \\ ${ }^{1}$ Dept. of Electronics and Communication Engineering \\ Hyderabad Institute of Technology and Management, \\ Gowdavelly (V), Medchal(M), Telangana, India \\ 1azeemunnisa.ece@hitam.org
}

\begin{abstract}
Students interaction in the online classroom with instructor is an important consideration in ensuring that students can improve their knowledge and reach a higher level of achievement in engineering courses. This study focuses on fostering student's interaction and improves learning for a course digital image processing offered in a private institution of higher education (HITAM) in Telangana, India. Interactive features includes most important synchronous discussions and polls in scheduled sessions, and which can be achieved via social media tools for sharing of information and resources. Qualitative student feedback was analysed regarding the new way of delivering the course. Findings indicated that students who attended weekly synchronous sessions valued online session as it give them more information about image visual than the traditional class. Problems identified included technical difficulties during synchronous sessions, absenteeism, participation was lacking on the questioning $\&$ discussion and inability to attend synchronous sessions due to scheduling of their individual class of interest like GRE etc. In addition, few students made use of the opportunity to interact via social media. While students expressed that the visual components of the course were valuable and helped them in qualifying the Assessments, several areas in which improvement may be made remain. This paper proposes blended online learning as one of the efficient method to improve learning. The analytical result from this study is shown, which is the comparison of online learning and blended online learning.
\end{abstract}

Keywords: Blended Online learning, Digital Image Processing, synchronous communication.

\section{Azeem Unnisa ${ }^{1}$ \\ ${ }^{1}$ Dept. of Electronics and Communication Engineering Hyderabad Institute of Technology and Management, Gowdavelly (V), Medchal(M), Telangana, India 1azeemunnisa.ece@hitam.org}

\section{Introduction}

In Today's world knowledge construction in students can be increased by combining technology with the traditional way of lecture delivery. Lecture delivery by instructor has to be converted to facilitator for student focused and engaged learning. The importance of engaged learning has been focused for many years by a number of learning theorists, who underlined the idea that effective learning in students can happen through operating jointly and engaging in discussion with fellow (Bornstein \& Bruner, 1989; Piaget, 1969; Vygotsky, 1981). Learner engagement has been found to be linked positively to the learning outcomes which are desirable such as critical thinking and higher grades (Carini, Kuh, \& Klein, 2006). Interaction can develop student engagement (Anderson, 2003), to ensure that students actively create their own knowledge via interaction in the classroom is an important consideration and reach a high level of achievement. In online courses, more likely issue is learner isolation and dropout by student, key component of learning is interaction (Conrad \& Donaldson, 2004). The main focus of online courses in the past although may have been content (Nipper, 1989), interaction is now recognized as playing a vital role in stimulating learning (Bernard et al. 2009; Lou, Bernard, \& Abrami, 2006; Norris, Mason, \&Lefrere, 2003). To promote a deeper level of thought and create meaning for the learner, activities involve collaboration and sharing of ideas among students (Conrad \& Donaldson, 2004). There are three types of interaction that have been identified and shown to support learning in online courses: 1) Interaction with content, including the ability of learners to access, synthesize manipulate, and communicate content information; 2) Interaction with instructors, or the ability of learners to communicate with instructor and receive feedback from their instructors; and 3) Interaction with classmates, i.e.; The ability of learners to communicate with each other about content to create an active learning community (Bernard et al., 2009; Moore, 1989).

In distance education courses, creating the most effective learning environment, course features is the one that has to encourage and must be selected with the three key types of interaction. Student-content interaction may take on different number of forms, including, interacting with 
multimedia, watching instructional videos as well as information searching (Abrami et al., 2011). A vibrant online community can be created when instructors facilitates sustained engagement with use specially designed assignments and course material (Hege, 2011). With regards to student-instructor interaction, integral component of a successful online course is the social presence of instructor, virtual interaction has to be converted into an impression of a "real" person by the instructor via performing activities that translate it (Dixson, 2012; Kehrwald, 2008). Interaction with students can be done by the instructors by incorporating both synchronous activities like telephone correspondence, and asynchronous, such as e-mail messages (Abrami et al., 2011). Similarly, to increase student to student interaction, synchronous activities, as in chatting or videoconferencing, or as in discussion boards which is asynchronous (Abrami et al., 2011), may be performed. The importance of meeting students where with regards to use of technology, and suggest that social media may be used as a way of encouraging students to participate in their learning experiences is the authors point (Everson, Gundlach, \& Miller, 2013). Individual learning has significantly less positive effects on student achievement when compare to small group and it was demonstrated by previous studies. (Lou, Abrami, \& d' Apollonia, 2001). To promote in the online environment, student-student interaction is particularly important. All three modes of interaction, however, have shown that each one favourably impacts student achievement by the research work (Bernard et al., 2009).

The critical component of delivering material in undergraduate science courses is the use of diverse techniques to foster interaction is, which are now being taught online to a greater degree than in the past.

In this paper, the proposed blended online learning method of teaching is implemented for IV year undergraduate students of electronics and communication engineering. Online learning methodology was found to be not fully effective due to various issues like lack of interaction, absenteeism, technical problems etc. Thus Digital image processing course was taught using blended online learning which is found to be more effective as it includes face to face interaction and also the use of technology. The Methodology followed will be discussed in the next section.

\section{Methodology (Blended online learning)}

The proposed methodology blended online learning comprises of a three-stage procedure to improve learning and interaction: 1) Traditional classroom teaching; 2) Project based learning in lab; and 3) Online classes. Figure1 shows the flow of the implementation of blended online learning using flowchart which shows all the three stages along with student feedback. This methodology is applied for every week, where out of five classes a week whole semester, three are traditional classes, one PBL Class in lab and one online Class. In all the three stages Plan- Do-Check- Act (PDCA) is followed. Each stage of methodology is explained below in detail below.

\section{A. Traditional classroom teaching:}

This is one of the important modes of teaching and it's the first stage of blended online learning as three hours per week is delivered in the traditional classroom. This plays a major role in achieving interaction between students and the instructor as well which is one of the most important part of engaged learning. Mathematical concepts can be delivered effectively using traditional way of teaching. As the course digital image processing comprises of a lot of algorithms which are used to process images to achieve better visual effects. Figure 2 shows Traditional Classroom, and the size of the class is 60 students. Students Feedback is collected after every week via minute paper in class and accordingly plan of action is done to improve the class.

This minute paper contains the following questions: 1) what aspects of the course content taught, students liked the best; 2) what aspects of the course content taught, students liked the least; 3) suggestions for improvements to the course delivery.

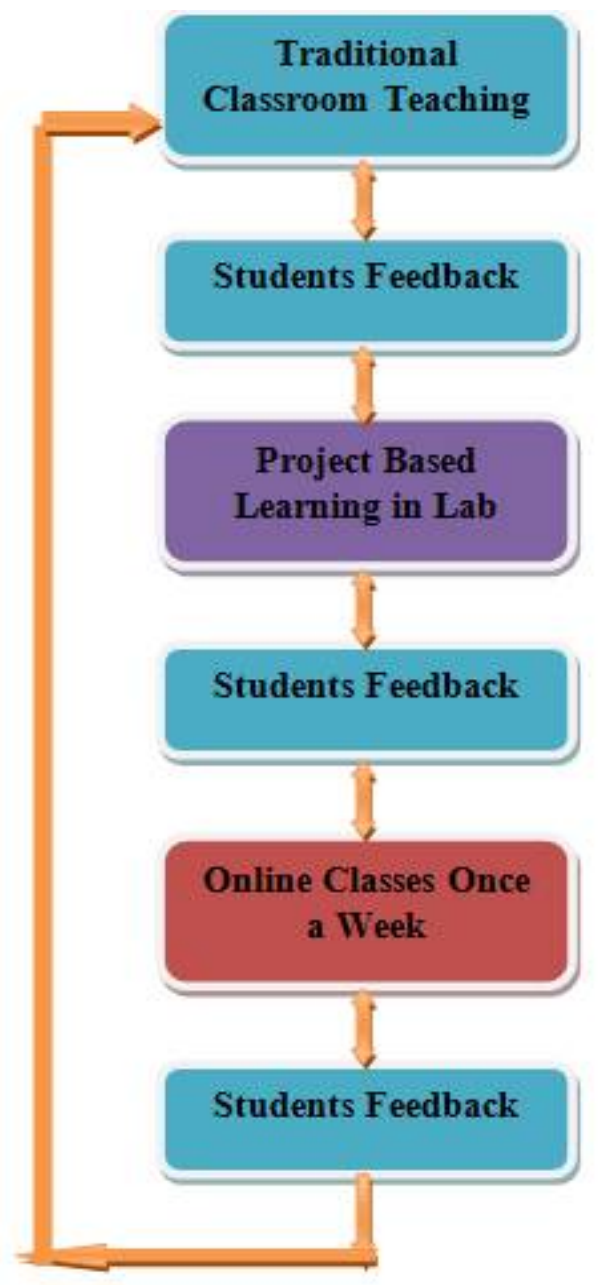

Figure1: Implementation of Blended Online Learning 


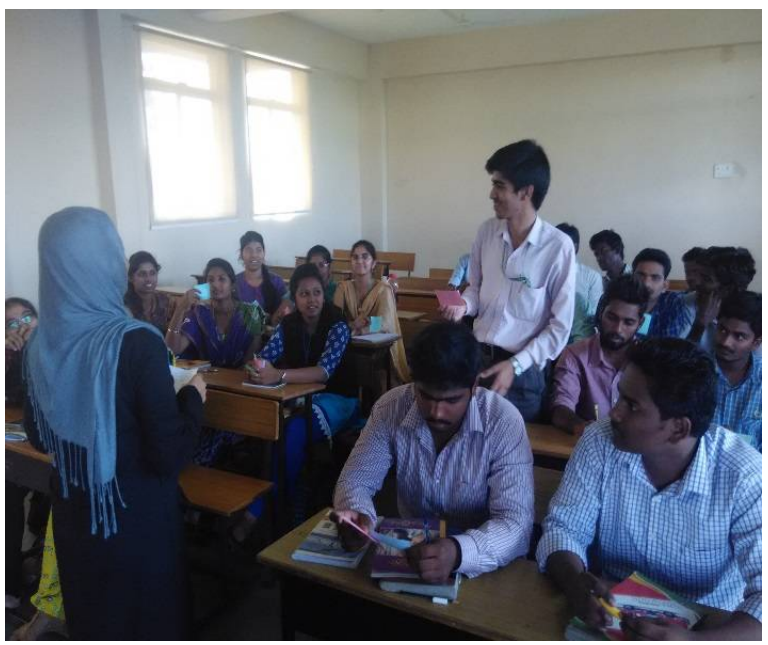

Figure 2: Traditional Classroom

\section{B. Project based learning in lab}

Project Based Learning (PBL) is one of the trending methodology used in almost all the institutions who are interested bringing transformation in the engineering education system. At HITAM, PBL is implemented to bring transformation from studying engineering to doing engineering. This course doesn't have any lab associated to it as it is designed by the university. Every week out of five theory classes assigned, one class is conducted in the lab. In Lab student actually implement the concepts learned in the traditional class. Projects are assigned to students in lab, where students works individually and in groups. Figure 3 shows the image of lab where students are working on projects using MATLAB and Figure 4 shows one of the output of Project Based Learning where the images are blended or fused. The attendance in Lab will be discussed in result section. Students Feedback was taken and analysed similar to traditional classroom and action was carried out.

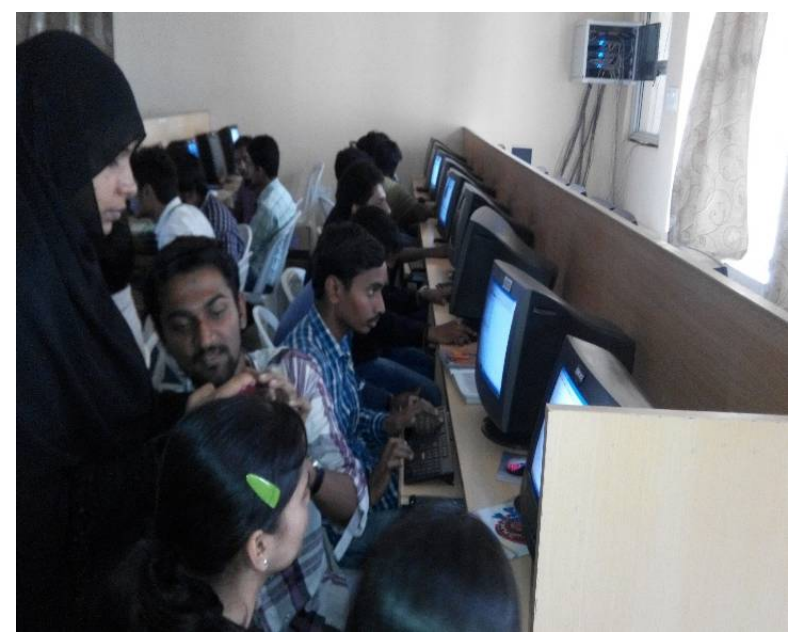

Figure 3:PBL in Lab
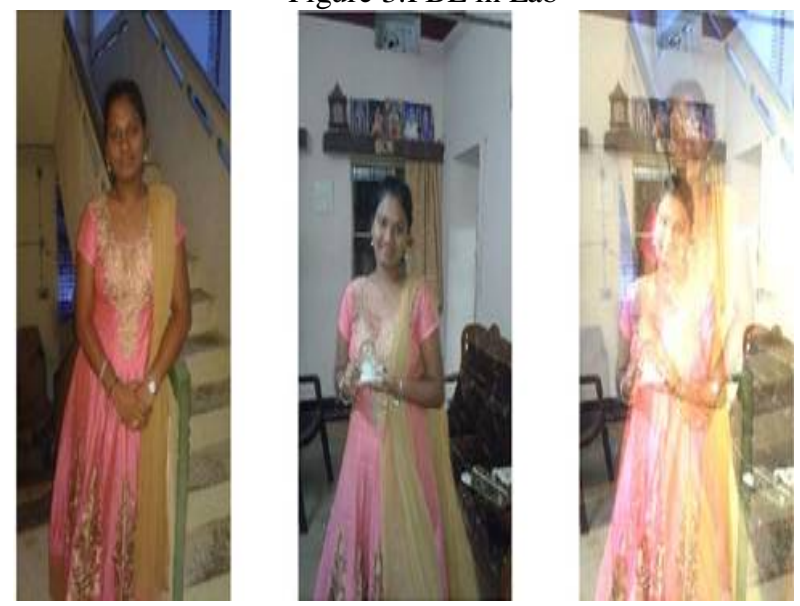

Figure 4: One of the PBL result

\section{Online classes}

Online Classes is the last stage of the blended online learning. Online classes are delivered via a different multimedia platforms such as GTM(Go to Meeting). Online classes required all the things to be well planned and executed. Online class is delivered once a week. First the link of the class is posted using social media like the google group and also on Facebook, students access the link and register for the meeting. The instructor and students get connected to eachother at the time of class. Figure 5 shows the starting of the online session where the presenter is about to start the class. The students are kept on mute mode while the lecture is delivered by the instructor but they can text their queries and instructor answers it during the session and also after the session. Students feedback is taken after every session and discussed in the traditional class and action is taken according to it. Figure 6 shows the first webinar on digital image processing.

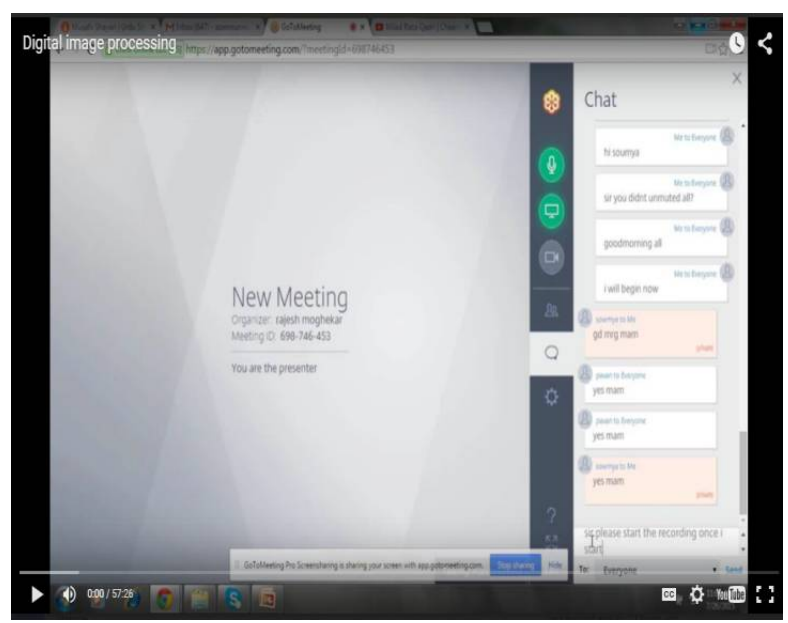


Figure 5: GTM tool for Online classes

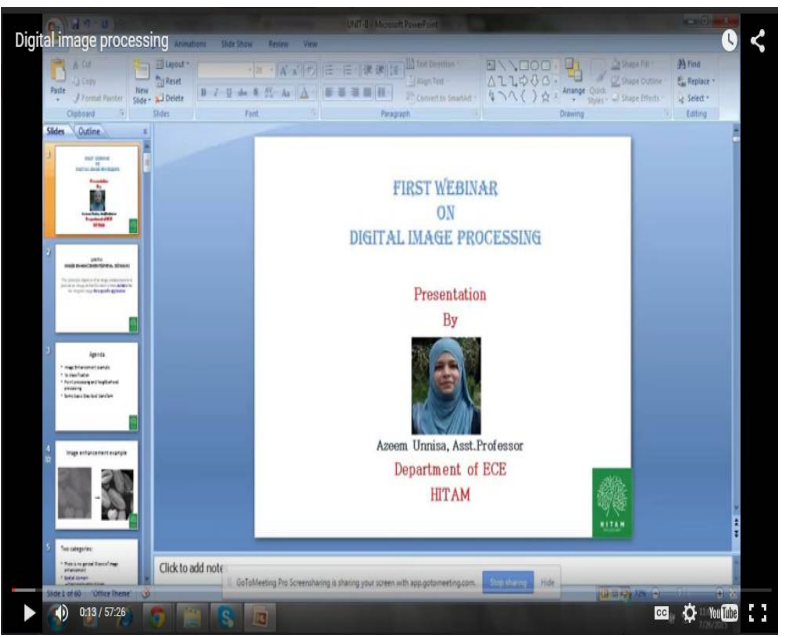

Figure 6: DIP First Webinar

The class was recorded and uploaded in YouTube for the students who were not able to attend the class. The recorded lecture link is being sent to students by social media tools like Face book and Google groups. One of the video can be found at:

https://youtu.be/ZfPAoZa5FkQ

It can be observed that three stages along with the student feedback can be called as blended online learning. In this methodology instructor can achieve more interaction with students and also among the student which plays a key role in improving learning.

The assessment of students is done according to the prescribed pattern of the university. The rate of success of this methodology will be discussed in the next section.

\section{Results and Discussion}

This section comprises five major outcomes of the study done on blended online learning. They are a) comparison of online vs. offline classes based on attendance, b) PBL classes attendance, c) comparative analysis of all the three stages of blended learning, d) ABCD analysis of the Formative assessment and e) comparison of online vs. blended online learning. Each of these outcomes is discussed in detail below.

\section{A. Comparison of Online vs. Offline Classes}

The Figure 7 shows the comparative analysis of online vs. offline classes based on the student attendance online and offline. From the figure it can be observed that the size of the class is 60 students, the data being compared is for three classes held online and the number of students viewed the lecture offline.It is observed that the strength of the students in online classes is very less about 20-30\% of the whole class where as the number of students who viewed the lecture recorded and uploaded on YouTube is very high. For example Figure 8 shows the number of views for a lecture of online class uploaded on YouTube which has 72 views.

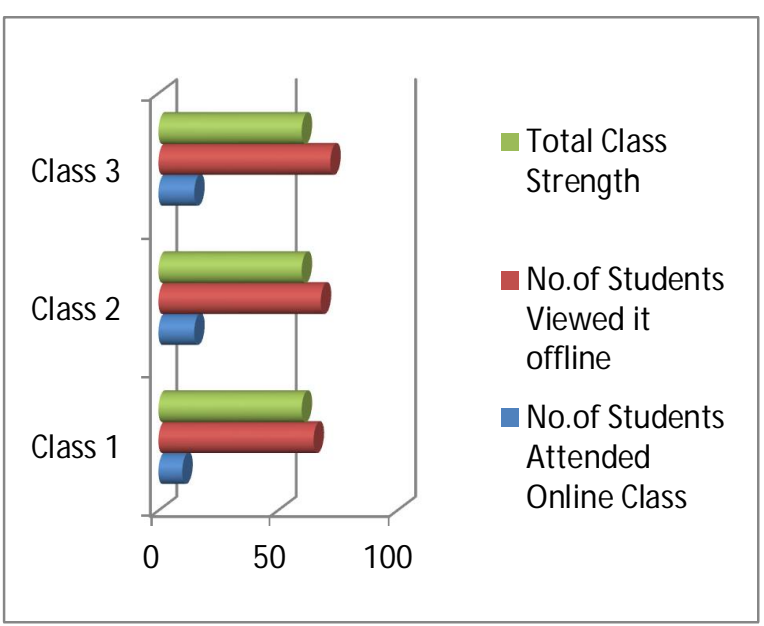

Figure 7: Comparison of Online Vs. Offline Tutorial

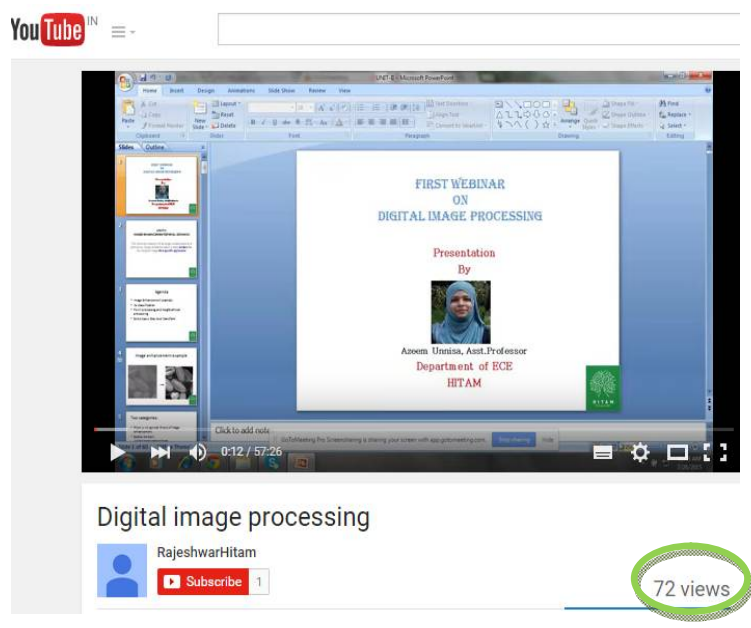

Figure 8: DIP online lecture on Youtube (Number of Views)

\section{B. PBL Classes Attendance}

Project Based Learning is the second stage of the blended online learning methodology which was conducted in lab. The lab was conducted once a week for the topics covered in the traditional classroom that week and also for the topics not covered for the better understanding and also application of the theory learned. Figure 9 shows the result PBL classes attendance for four classes and it is observed that the attendance is improved from below $50 \%$ to $75 \%$. Figure 10 shows one of the assignment output done by the students. It was found from student feedback that they have learned the course well by doing it practically in Lab. The lab was conducted once a week for the topics covered in the traditional classroom that week and also for the topics not covered for the better understanding and also application of the theory learned. 


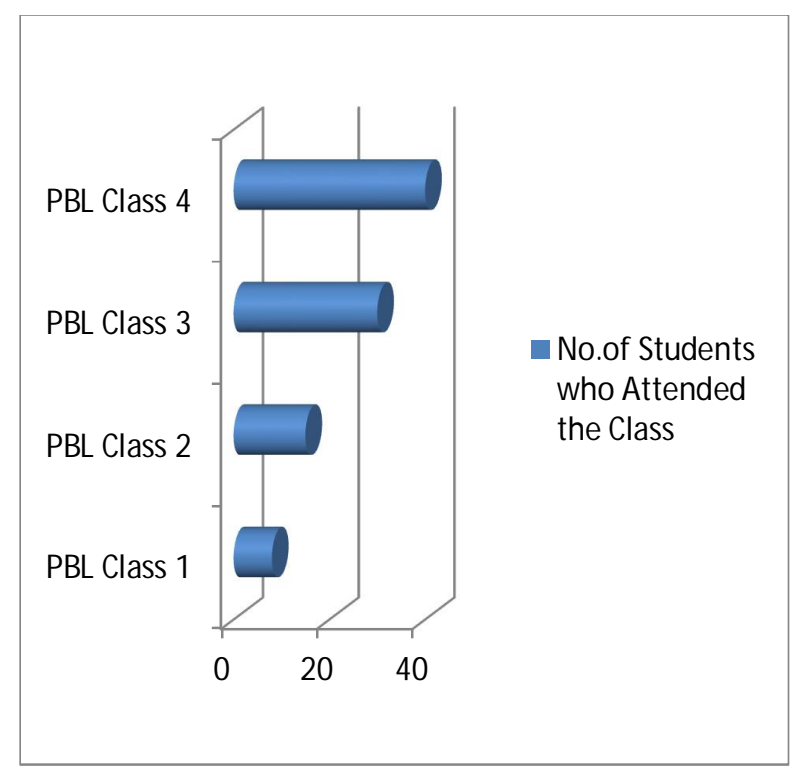

Figure 9: PBL Classes Attendance

The lab was conducted once a week for the topics covered in the traditional classroom that week and also for the topics not covered for the better understanding and also application of the theory learned. Figure 9 shows the result PBL classes attendance for four classes and it is observed that the attendance is improved from below $50 \%$ to $75 \%$. Figure 10 shows one of the assignment output done by the students. It was found from student feedback that they have learned the course well by doing it practically in Lab.
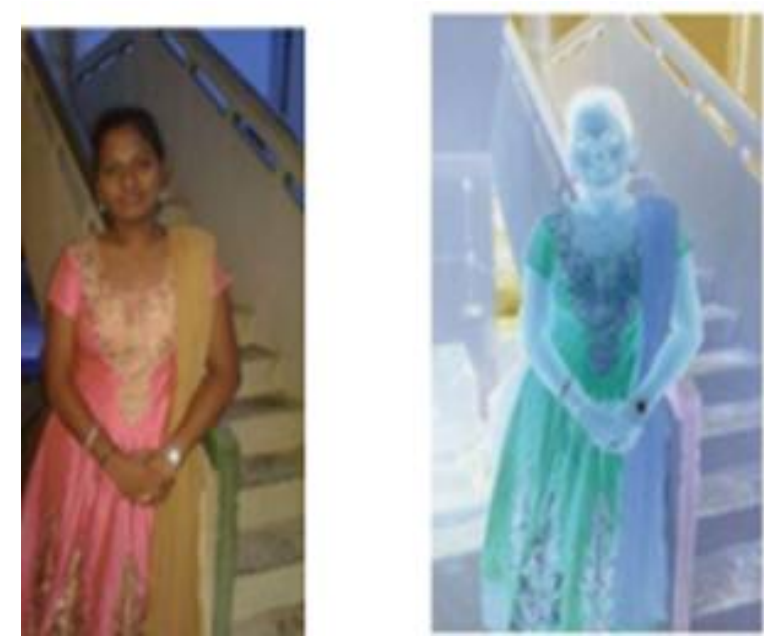

Figure 10: Assignment output (Generating image negative)

C. Comparative analysis of 3 stages of blended learning

The three stages of blended online learning is compared based on the attendance percentage in the classes for four weeks.

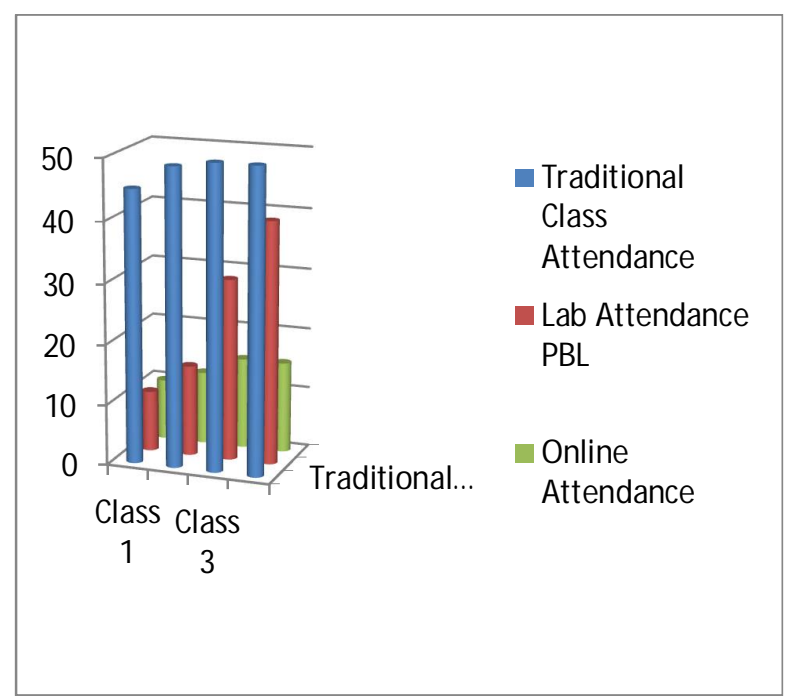

Figure 11: Blended Online Learning Analysis

The three stages of blended online learning is compared based on the attendance percentage in the classes for four weeks. It is found that traditional classroom percentage is more in all the four cases where as online class its less and PBL class its moderate. Thus it can be concluded that only online class alone cannot work in this course .It has to be blended online learning.

\section{Category - A, B, C, D Performance Analysis}

Table 1 shows the performance analysis of formative assessment of the course being taught using Blended Online Learning method. It is found that out of the class size of 60 students, 30 students are under a category, 15 students are under B category, 10 are under $\mathrm{C}$ category and 5 are under D category. The A, B, C, D category is mentioned in the table below for a total of 25 marks of formative assessment. Thus it is observed that less number of students is under poor category of about $10-15 \%$ which can be still improved based on the quality enclosure loop cycle followed in this method i.e; Plan-Do-Check-Act (PDCA cycle).

Table 1: A, B, C, D Performance Analysis

\begin{tabular}{|l|l|}
\hline \multicolumn{1}{|c|}{ Category } & No. of Students \\
\hline $\mathbf{A}(>=19)$ & 30 \\
\hline $\mathbf{B}(15-18)$ & 15 \\
\hline $\mathbf{C}(10-14)$ & 10 \\
\hline$D(<=9)$ & 5 \\
\hline
\end{tabular}

E. Comparison of Online vs. Blended Online Learning 
Student feedback was taken after conducting the online sessions and the feedback shows that they didn't like the course to be delivered fully online.

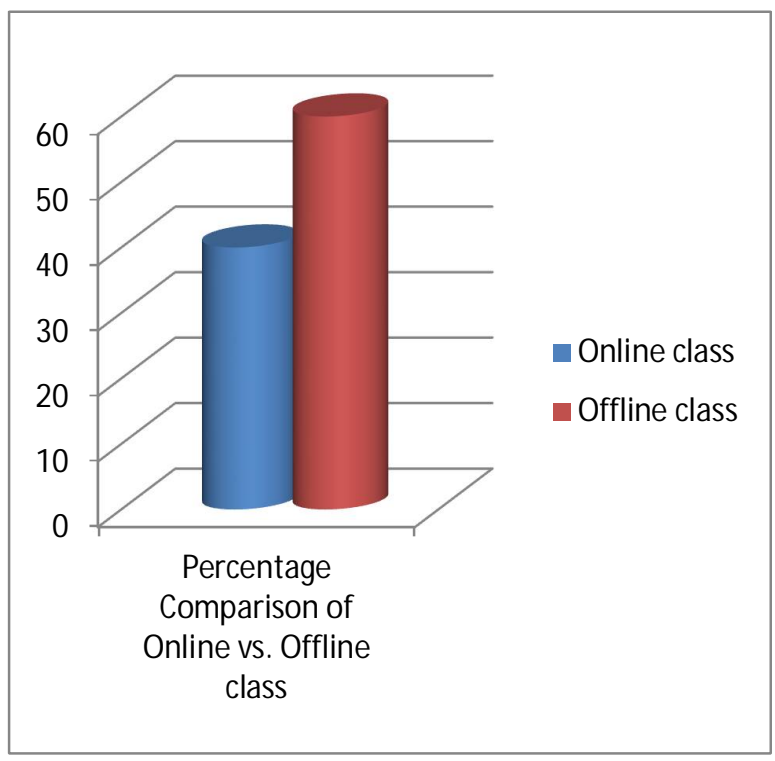

Figure 12: Comparison of Online vs. Blended Online Learning

The feedback shows that $35 \%$ of the students opted online class and remaining did not opted due to various issues like technical problems, mismatch in timings and social media distraction, less interactionetc.

\section{Conclusions and Recommendations}

Different issues were revealed from students that live sessions attendance was found to be less and they perceived extra classes and discussion with instructor and peers for participation and learning. However, as not all students were able to attend these sessions due to scheduling issues or other reasons, the issue of inequality has raised. Recordings were shared on the Social network like YouTube and link was posted to the class group and upon winding up of each session, viewing a recording is not similar to having the opportunity to engage and participate in live conversation with peers and instructor. Thus blended Online learning was designed to deliver the course keeping all the category students in mind and it was found to be effective as it has improved the result and also inculcated project based learning skills which is very important to enter in industrial world as an engineer.

For better results, attractive media tools should be used which can help to improve interaction between the students and also the instructor, activities should be included in the online classes like polls, discussion boards etc.

\section{References}

1.Abrami, P. C., Bernard, R. M., Bures, E. M., Borokhovski, E., \& Tamim, R. M. (2011). Interaction in distance education and online learning: Using evidence and theory to improve practice. Journal of Computing in
Higher Education, 23, 83-103. doi:10.1007/s12528-0119043-x

2. Anderson, T. (2003). Modes of interaction in distance education: Recent developments and research questions. In M.G. Moore \& W. G. Anderson (Ed.), Handbook of Distance Education. Mahwah, New Jersey: Lawrence Erlbaum Associates Inc. Arteaga Sánchez R.., Cortijo V., \&Javed U. (2014). Students' perceptions of Facebook for academic purposes. Computers \& Education, 70, 138-149. doi:10.1016/j.compedu.2013.08.012

3. Bernard, R. M., Abrami, P. C., Borokhovski, E., Wade, C. A., Tamim R. M., Surkes M. A., \& Bethel, E. C. (2009). A meta-analysis of three types of interaction treatments in distance education. Review of Educational Research, 79(3), 1243-1289.

4. Bornstein, M. H., \& Bruner, J. S. (1989).In Interaction in Human Development. Hillsdale, New Jersey: Lawrence Erlbaum Associates Inc.

5. Carini R. M., Kuh G. D., \& Klein S. P. (2006). Student engagement and student learning: Testing the linkages. Research in Higher Education, 47(1), 1-32. doi:10.1007/s11162-005-8150-9

6. Conrad, R., \& Donaldson, J. (2004). Engaging the Online Learner: Activities and Resources for CreativeInstruction. San Francisco, California: John Wiley \& Sons, Inc.

7. Dixson M. D. (2010). Creating effective student engagement in online courses: What do students find engaging? The Journal of Scholarship of Teaching and Learning, 10(2), 1-13.

8. Everson M., Gundlach E., \& Miller, J. (2013). Social media and the introductory statistics course. Computers in Human Behaviour, 29(5), A69-A81. doi:10.1016/j.chb.2012.12.033

9. Hege B. A. R. (2011). The online theology classroom: Strategies for engaging a community of distance learners in a hybrid model of online education. Teaching Theology \& Religion, 14(1), 13-20.doi:10.1111/j.14679647.2010.00668.x

10. Joosten T. (2012). Social Media for Educators: Strategies and Best Practices. Hoboken, New Jersey:John Wiley \& Sons, Inc.

11. Kehrwald B. (2008). Understanding social presence in text-based online learning environments. DistanceEducation, 29(1), 89-106. doi:10.1080/01587910802004860

12. Lou Y., Abrami, P. C., \& d' Apollonia S. (2001). Small group and individual learning with technology: Ameta-analysis. Review of Educational Research, 71(3), 449-5 